\title{
PEDAGOGIA DIALÓGICA DE AFETO E LIBERTAÇÃO: UMA REFLEXÃO A PARTIR DA PRÁTICA DA PROFESSORA LU̧ANA TOLENTINO
}

\section{DIALOGICAL PEDAGOGY OF AFFECT AND RELEASE: A REFLECTION FROM THE PRACTICE OF TEACHER LUANA TOLENTINO}

\section{Isabelle Rocha Nobre*}

Resumo: Freire percebe a realidade como um processo, um eterno devenir, em que a solidariedade entre os indivíduos e o mundo é fator indispensável para o pensar verdadeiro e, o consequentemente, para um diálogo verdadeiro. Entretanto, para que esse diálogo de fato possa lograr êxito, nos adverte que não se pode prescindir de que tenham voz, isto é, se um indivíduo, ou grupo de indivíduos, está na condição de oprimido em sua liberdade de fala, limitado, enquanto o outro. Nega este o direito de dizer a palavra não há entre estes a possibilidade de troca. Portanto, é preciso que primeiro todos conquistem o direito aos espaços necessários de fala para que entre todos possa existir um ato de criação solidário e plural. Porém, embora facilmente observáveis os danos ocasionados por uma produção de conhecimento excludente, os mecanismos para alterar tal quadro são pouco aplicados. O presente trabalho busca demonstrar uma alternativa de educação dialógica pautada no afeto implementada por uma professora mineira na Educação Fundamental através de práticas pedagógicas feministas, antirracistas e inclusivas.

Palavras-chave: Educação. Direitos Humanos. Afeto. Epistemologia feminista negra.

Abstract: Freire perceives reality as a process, an eternal becoming, in which solidarity between individuals and the world is an indispensable factor for true thinking and, consequently, for true dialogue. However, in order for this dialogue to succeed, it warns us that one can not do without everyone having a voice, that is, if an individual, or group of individuals, is in the condition of being oppressed in his limited freedom of speech, while the other denies this the right to say the word, there is no possibility of dialogue between them. Therefore, it is necessary that everyone first conquer the right to the necessary spaces of speech so that among all there may be an act of solidarity and plural creation. However, although the damage caused by the production of exclusive knowledge is easily observable, the mechanisms to change such a framework are little applied. The present work seeks to demonstrate an alternative of dialogic education based on the affection implemented by a Minas Gerais teacher in Fundamental Education through feminist, antiracist and inclusive pedagogical practices.

\footnotetext{
* Possui graduação em Direito pela Pontifícia Universidade Católica do Rio de Janeiro (2015). Atua como advogada - Ordem dos Advogados do Brasil - Seccional do Rio de Janeiro e Técnica em assuntos educacionais na UFRJ. E-mail: isabellernobre@gmail.com.
} 
E LIBERTAÇÃO:...

Keywords: Education. Human rights. Affection. Black feminist epistemology. 


\title{
1 O QUE A GENTE TEM FEITO? UM CONTO E UM PONTO.
}

\author{
me levanto \\ sobre o sacrifício \\ de um milhão de mulheres que vieram antes \\ e penso \\ o que é que eu faço \\ para tornar essa montanha mais alta \\ para que as mulheres que vierem depois de mim \\ possam ver além \\ Legado. \\ (KAUR, 2018).
}

Naquela tarde o sol saía tão rápido que era possível ver se apagando uma a uma as pequenas frestas de luz que se projetavam na parede. A veneziana semiaberta deixava de ser iluminada enquanto eu acompanhava deitada na cama a parede branca voltar a ser branca, sem texturas, sem reflexos. Surgiu nesse momento uma vontade imensa de construir a casa de bonecas e ela não precisaria passar da altura da cintura de uma pessoa mediana de pé. Pensava na madeira a utilizar, na sua espessura, nas seis divisões que seriam empilhadas duas a duas em três andares, e o vão que recortaria pelo meio de todas a fim de passar uma escada em caracol, ou dois lances divididos em um ângulo reto, aproximadamente na altura do meio do andar. Mas e quanto à acessibilidade? Seria preciso um elevador certamente, mas como fazer? Um jogo de pesos através de uma roldana que se adequasse ao que se quisesse transportar. Um mecanismo dependente do manipulador para suspender as cordas e prendê-las num pequeno gancho de metal na base da casa. E quanto à iluminação? Assim como naquela tarde, não poderia esperar que sempre o sol fosse suficiente. Não poderia supor razoável confiar na vontade de que as frestas de luz se mantivessem pelo tempo necessário. Seria preciso luz elétrica. Ora, e como fazer? Enumerei as possibilidades de estudar elétrica, pequenos fundamentos para pequenos cientistas, pesquisadores amadores que necessitam de soluções rápidas, ideias eficazes para fazer sozinho. Não existiria tempo que bastasse. Nada parecia adequado ou acessível, tampouco existiam garantias da eficácia dos métodos. Levantei um tanto quanto contrariada e supus a ideia de pintar as paredes, fazer texturas, usar tecidos diversos para trazer a harmonia que pretendia a cada cômodo. Em poucos instantes um sem fim de imagens se sobrepuseram trazendo consistência às sensações pretendidas para 
cada pedaço da construção. Em poucos instantes também, a materialidade dos problemas anteriores se desfizeram em poeira. Toda a atenção agora se voltava para a estética do lugar que se visualizava. Percebi meu equívoco. Nós construímos ideias que buscam uma razão consciente e um fim significativo, mas não investimos o tempo necessário para que o método alcance o escopo inicial. Não basta a perfumaria. Não bastam as paredes e sua energia. Quanto a nossa casa é verdadeiramente iluminada e inclusiva e não dependente de fatores externos é quanto ela poderá ser efetivamente uma casa. Funcional e adequada a todos. Quanto a educação é verdadeiramente iluminada e inclusiva e não dependente de fatores externos é quanto ela poderá ser efetivamente educação. Funcional e adequada a todos.

\section{SERÁ QUE TÁ CERTO FAZER ASSIM? [OU INTRODUÇÃO]}

Se estamos em um mundo diverso, com inúmeras possibilidades de interações entre os indivíduos, que sentido teria pensar em uma construção de conhecimento que não pudesse lidar com essa variedade?

Para Paulo Freire (1987), é a palavra autêntica que pode transformar o mundo, isto é, apenas quando pronunciamos o mundo vinculando ação e reflexão podemos alcançar uma prática transformadora na produção de conhecimento. Caso alguém pretenda dizer/ensinar a outro um determinado conhecimento sem levar em consideração a participação de ambos no processo de construção do conhecimento, este será vazio, prescritivo e pouco eficaz.

Desse modo, se o educador apenas age, sem refletir, incorre na falha de agir por agir, trata-se de uma ação desprovida de pensamento crítico. Por outro lado, se apenas privilegia-se a reflexão, em detrimento da ação, emite-se uma palavra oca, alienante e alienada, que não oferece transformação por quem a recebe, que não reverbera individualmente, uma vez que não admite as singularidades de cada um.

A quem interessa manter uma educação não dialógica? Porque não investimos em uma epistemologia que se pretenda emancipadora? Certamente há quem tenha ganhos com esse modelo, a quem Freire (1987) chama de 
dominadores, os indivíduos que ganham com a não emancipação dos demais, aqueles que atuam sobre outros indivíduos castrando-os, doutrinando-os a fim de garantir que enxerguem a realidade como intocável e não passível de mudanças, uma realidade estática que não permite interferências de indivíduos comuns, que não seriam competentes para absorvê-la e ressignificá-la.

A epistemologia negra e feminista é, nesse sentido, uma possibilidade emancipadora essencialmente dialética, e o diálogo pressupõe a existência de pelo menos duas pessoas em uma relação de ensino recíproco e constante, quando em um ambiente de produção de conhecimento, como postulado por Freire (1987).

A epistemologia proposta é paradigmática em sua resposta não salvadora àqueles que estão oprimidos em sua consciência, pois não pretende transmitir uma mensagem pronta, um conhecimento acabado que retire da ignorância os indivíduos que Freire denomina hospedeiros de opressores, ao contrário, pretende propiciar variados níveis de percepção de si aos indivíduos, e ao mundo em que estão. Nesse sentido, diz Freire, em sua obra Pedagogia do Oprimido, que "nosso papel não é falar ao povo sobre a nossa visão do mundo, ou tentar impô-la a ele, mas dialogar com ele sobre a sua e a nossa." (FREIRE, 1987).

A tomada de consciência por parte dos indivíduos sobre si mesmos os capacita a gerir seus próprios conflitos e perceber as temáticas pertinentes às suas questões, de modo que inaugura-se uma epistemologia inclusiva e libertadora, partindo de sua constituição histórica e social, de sua significação e ressignificação, de sua pluralidade, portanto, diametralmente oposta daquela objetiva, racional e com pretensões de universalidade.

Daí porque a complexidade observável no mundo, deva ser absorvida, tanto quanto possível, na investigação de temáticas pertinentes, e como absorver temáticas que abordam a diversidade partindo de uma epistemologia compartimentalizada? Estaríamos fadados a manutenção de estereótipos excludentes e desalinhados dessa complexidade já mencionada, é preciso fazer diferente. 


\section{MAS ALGUÉM JÁ TESTOU ISSO? [OU METODOLOGIA E RESULTADOS]}

Ao ler a professora mineira Luana Tolentino e perceber sua prática de ensino nenhum dos objetivos de uma educação pautada no afeto parece distante ou irrealizável. Sua obra Outra Educação é Possível, há pouco lançada e publicada pela Mazza Edições, editora comprometida com publicações afro-brasileiras, é fruto de muitos anos de uma atividade docente comprometida e bem instrumentada.

Seu livro é orquestrado de uma maneira simples e direta, e talvez esta seja sua maior valia, pois não há conhecimento acadêmico que se legitime quando não consegue alcançar fora dos muros da universidade.

O presente artigo busca apresentar através da metodologia descritiva os meios pelos quais se concretiza a educação pautada no afeto. A pesquisa será realizada através de revisão bibliográfica e de um estudo de caso da obra citada a fim de descrever, delimitar e interpretar as práticas pedagógicas utilizadas.

A aplicação de conceitos que parecem teóricos e abstratos é por vezes emocionante, além de contundente no ponto da nossa mente que apreende e não põe em prática seus valores e ideais. De fato, outra educação torna-se possível quando a capacitação promove não só um encorajamento pessoal, mas uma atuação efetiva, desvinculada da utopia limitante que a muitos submete.

A partir de uma série de contos/relatos podemos ver que a professora de Educação Fundamental aplica à sua participativa plateia uma série de teorias comuns em terminologia acadêmica e pouco realizada nos níveis mais básicos de ensino.

Ao realizar com seus alunos um projeto denominado \#NovembroNegro a autora levou para análise o funk carioca Rap da Felicidade, dos compositores Cidinho e Doca, a fim de abordar o conteúdo de História e Cultura Afro-Americana, já previstos como obrigatórios em lei desde 2003 (Lei № 10.639/03), e em seguida gravou um vídeo com toda a turma cantando junto. Em suas palavras: "Está tudo lá: a segregação da população preta e pobre desde o período pós-abolição, os privilégios das elites e das classes médias, além do olhar de desprezo." (TOLENTINO, 2018, p. 23 e 24). 
Em outra prática pedagógica, a professora incentivou aos alunos que pesquisassem a respeito de alguns escritores afro-brasileiros, enumerados por ela, sem deixar que soubessem a raça destes, para que pudessem constatar a contribuição significativa do povo negro na Literatura Brasileira, e questionar junto a turma porque muitos desconheciam tais personagens, ou desconheciam seu pertencimento racial.

Mais um projeto desenvolvido na escola mineira que a autora leciona foi o Gênero e Raça em sala de aula, que pretendia trazer as vivências pessoais dos alunos para a discussão a fim de construir uma identidade racial e de gênero desconstruindo preconceitos.

Posteriormente, através de uma parceria institucional com o Grupo de Pesquisas Mulheres em Letras e do Núcleo de Estudos Interdisciplinares de Alteridade (NEIA) vinculados à Faculdade de Letras da Universidade Federal de Minas Gerais (UFMG), Luana Tolentino propôs um projeto de troca de cartas dos seus alunos com os alunos moçambicanos da Escola Secundária de Barada, possibilitando uma ponte real entre vivências que poderiam apresentar mais congruências que divergências.

O brilhantismo da professora, mais do que acreditar na possibilidade de transformação social operada pela educação inclusiva, feminista e antirracista, está na construção de redes. As cartas foram enviadas e recebidas a partir de uma parceria com o Consulado Moçambicano em Minas Gerais, e em seguida o Projeto tornou-se documentário através da parceria com a ONG Ação Imagem Comunitária (AIC) que trabalha com juventudes periféricas, que levou uma das suas alunas a falar: "- Professora, até que enfim a nossa escola está sendo filmado por uma coisa boa! - Dias antes, várias equipes de reportagem estiveram lá para registrar o assassinato de um aluno." (TOLENTINO, 2018, p. 39).

Quanto à questão indígena, pauta muitas vezes deixada de lado na tentativa de inclusão, mesmo sob determinação legal (Lei № 11.645/08), foi trabalhada pela professora Luana através do Projeto Entre Passado e Presente: Povos Indígenas no Brasil. Foi elaborada uma apostila a partir da leitura de materiais acadêmicos e noticiários adaptados pela professora para a faixa etária da sua turma. 
A pesquisa foi tão bem acolhida pelos alunos que a professora acabou por descobrir a presença de uma aluna indígena Kambeba na UFMG, que aceitou um convite para palestrar para todas as turmas de Ensino Médio na escola trazendo novas perspectivas ao contar que havia deixado sua família no Norte do país para estudar medicina.

Em outro Projeto denominado Vale do Jequitinhonha: Arte, História e Memória, a autora uniu o conteúdo sobre o Renascimento na Europa, com a discussão sobre outras formas de saber muitas vezes subalternizadas, como a dessa região mineira.

Além dos Projetos com pauta direta, sua docência também muito impressiona por trazer meios não usuais, que entendem o indivíduo em sua totalidade na produção do conhecimento. Ao inserir a meditação em suas aulas, a autora mostra que uma educação holística pode oferecer inúmeros benefícios, deixando, por exemplo, os alunos mais suscetíveis uns aos outros e ao conteúdo.

Enquanto a realidade muitas vezes brutaliza a mente e as relações humanas, Luana funda em sua classe um compromisso com o afeto. Ao pedir que os alunos se abraçassem após uma prática meditativa, auxilia a criação de novos padrões comportamentais entre estes, inclusive em turmas que eram descritas como difíceis de lidar em seu ambiente escolar, pois silencia a mente e amplia a consciência sobre as próprias ações, equilibrando assim emoções conflituosas ou não corretamente acessadas.

O Projeto Cartas de Amor surgiu como a busca de uma oportunidade para que os alunos pudessem expressar seus sentimentos através da escrita, em que os alunos foram estimulados a escrever para pessoas internadas em um hospital local. Enquanto desenvolviam a escrita e a leitura de forma eficaz, o principal desejo era de enviar mensagens de força e afeto para pessoas que nem sequer conheciam.

Quanto à inclusão de alunos que apresentavam alguma atipicidade, Luana também não foi omissa, uma aluna com comprometimento visual promoveu uma adaptação na maneira que a professora transmitia os conteúdos que passou a ser predominantemente oral, ou em textos impressos com letras maiores que a incentivaram a participar das aulas lendo; uma aluna com limitações de movimentos por um problema na coluna que se identificou com a história de vida de Frida Kahlo 
trazida pela professora para um debate sobre nossas referências latino-americanas; e um aluno com atipicidade mental que se sentiu parte no momento que a formação circular passou a nortear as aulas.

Por fim, posso dizer que um dos capítulos que mais me impactou pessoalmente [e me fez escrever este artigo] foi o que a autora traz a importância de um debate consciente, mediado e fundamentado sobre Educação em Direitos Humanos. Ao perceber que em geral estava difundida entre seus alunos o discurso de que isso serviria para "proteger bandidos", Luana apresenta uma perspectiva histórica e as lutas incessantes de muitos para a promoção de tais direitos.

Ainda mais motivador é ler sobre a metodologia utilizada pela professora ao descrever os debates animados que ocorriam em círculos, com atividades feitas em duplas ou grupos, em que todos tinham voz e oportunidade real de expressar suas opiniões, sem invisibilizações e, assim, construir juntos novos conhecimentos, além de oferecerem sugestões para debates futuros, por exemplo, em temas como homofobia, intolerância religiosa e racismo.

Ao demonstrar a aplicabilidade da teoria em sua docência, Luana testou e atestou a eficácia de uma educação pautada no amor e no respeito, em suas palavras: "Acredito que uma educação libertadora é fundamental para a desnaturalização e para o enfrentamento das desigualdades historicamente construídas pelas classes dominantes." (TOLENTINO, 2018, p. 106).

\section{E O QUE É FUNDAMENTAL NESSA PROPOSTA? [OU DISCUSSÃO]}

As práticas da professora Luana enfatizam um sentimento observado na leitura de obras como a de Bell Hooks e Maya Angelou, ambas autoras abordando a segregação e marginalização das pessoas negras nos Estados Unidos. As sólidas bases das autoras americanas que abordam comunidades segregadas histórica e institucionalmente se aplicam, em grande medida, à turma segregada nas periferias da capital mineira. A correspondência que se promove entre comunidades marginalizadas alcança a lógica operada na realidade latino americana.

O modelo de educação não bancária da prática docente de Luana condensa o postulado por Freire e por Bell Hooks, quando não restringe a educação à 
capacidade de reproduzir aquilo que foi transmitido, antes disso tem o ato primeiro na confiança da potencialidade de cada aluno desenvolver por seus processos e vivências o conhecimento que se pretende alcançar conjuntamente.

Embora o processo de construção dentro de uma lógica excludente possa comprometer o aprendizado, nesta proposta pedagógica fica evidenciada a possibilidade de ressignificação dos processos. Apresenta-se assim uma proposta válida e levada a termo mesmo sob difíceis ou desafiadoras condições tanto institucionais quanto sociais da educação tradicional.

Ao relatar a educação pós segregacionismo nas escolas estadunidenses, Bell Hooks demonstra a profunda transformação sentida quando as escolas passaram a ter alunos de diferentes raças, em suas palavras.

\begin{abstract}
De repente passamos a ter aulas com professores brancos cujas lições reforçam os estereótipos racistas. Para as crianças negras, a educação já não tinha a ver com a prática da liberdade. Quando percebi isso, perdi o gosto pela escola. A sala de aula já não era um lugar de prazer ou de êxtase. A escola ainda era um ambiente político, pois éramos obrigados a enfrentar a todo momento os pressupostos racistas dos brancos, de que éramos geneticamente inferiores, menos capacitados que os colegas, até incapazes de aprender. (HOOKS, 2013, p. 12).
\end{abstract}

Narrando também o momento de segregação estadunidense, Maya Angelou demonstra as diferenças sociais que se operavam entre negros e brancos nas escolas segregadas de onde passou sua primeira infância, em Stamps, e posteriormente, quando foi morar com a mãe e frequentar escolas mistas em St. Luís, em que os professores "andavam de pernas fechadas e falavam com lábios apertados, como se tivessem tanto medo de deixar o som sair quanto tinham de inspirar o ar sujo que o ouvinte expirava." (ANGELOU, 2018, p. 84).

De semelhante modo, a educação operada através das práticas pedagógicas de Luana busca fornecer ao aluno que se sente desprestigiado pelo modelo vigente uma nova alternativa de aprendizado, ou antes, de ser reconhecido como sujeito do processo de aprendizagem. Retomar ao aluno marginalizado, por condições sociais ou étnicas, seu protagonismo revigora o pressuposto que deveria ser essencial em uma educação libertadora, qual seja, dar voz.

A prática docente da professora mineira privilegia o olhar apurado frente às necessidades expressas por cada aluno, como uma pessoa total e complexa, se 
opondo diametralmente a educação bancária, e respeitando o tempo que uma educação crítica e consciente requer.

Interessante notar que a pedagogia proposta por Bell Hooks, e seguida por Luana, não se pretende manualística, pois reconhece em cada sala de aula uma essência única que varia dependendo da relação que se estabeleça entre alunos, professores e práticas pedagógicas.

A autora entende o papel do professor como um "catalisador", que almeja inspirar os alunos e fazê-los confiantes da necessidade de se engajarem e comprometerem com a mudança no modo de aprender, gerando uma adequação institucional e sistêmica.

Ao propor um vínculo real entre a plateia, conjuntamente responsável pela produção de conhecimento a partir de relações horizontais pressupõe um momento de ruptura paradigmático num modelo que se estende por gerações, mesmo já tendo demonstrado seu evidente fracasso.

Há que se levantar ainda que tal possibilidade dialógica, conforme descrita em sua obra requer um componente fundamental: o amor. O amor, descrito por Freire (1987), é tarefa essencial na relação entre indivíduos que não interagem em relações de dominação, ao contrário, é base fundante para a libertação mútua, atuando na luta contra opressões, conforme podemos ver em trecho de sua obra:

\footnotetext{
Quem, melhor que os oprimidos, se encontrará preparado para entender o significado terrível de uma sociedade opressora? Quem sentirá, melhor que eles, os efeitos da opressão? Quem, mais que eles, para ir compreendendo a necessidade da libertação? Libertação a que não chegarão pelo acaso, mas pela práxis de sua busca; pelo conhecimento e reconhecimento da necessidade de lutar por ela. (FREIRE, 1987, p. 17).
}

Através do reconhecimento do outro como um outro eu, o amor opera estabelecendo liames que permitem contribuições entre os indivíduos que se doam e recebem reciprocamente. No amor fundante a relação dialógica alcança seu apogeu, se tornando criadora e transformadora, pois cada um é corresponsável em uma construção coletiva de conhecimento.

A construção coletiva ancorada no amor é, assim entendo, possível apenas pela confiança mútua entre as partes, que se desprendem de sua individualidade e 
do sentimento de competição para então estabelecer uma relação de coletividade e solidariedade, que a todos propicia evolução.

Esse amor, descrito por Freire, encontra ressonância na obra de Bell Hooks, quando afirma que sua força transformadora é uma das maiores quando se trata de quebrar as estruturas sociais existentes.

Para a autora, o amor quando assumido enquanto prática afetiva e social, é capaz de alterar as lentes com as quais olhamos para o passado, e nesse sentido, possibilita uma ressignificação da história e os alicerces para a construção de um novo caminho, participativo e acolhedor.

Ora, tanto mais necessário para a construção de outra epistemologia que o paradigma do amor, da dialogicidade e do afeto. A descolonização sob essa ótica iniciaria de forma a exteriorizar porções internas de sujeitos subalternizados, isto é, tornar-se-ia público tudo aquilo que é forçosamente mantido na seara privada da vida.

Ao nos abrirmos para o amor como método possível de lidar e construir as relações nos abriríamos também para enxergar o outro em suas potências e singularidades, e tanto mais interessante e pertinente como estratégia de descolonização do saber.

Ao dizer que o amor cura, Bell Hooks se identifica com um amor descolonizado. É preciso descolonizar o amor. É preciso desformalizar o ato de amar. Essa proposta pedagógica fundada no amor e na construção de afetos recíprocos é o que há de transformador e revolucionário na prática docente de Luana Tolentino.

A prática pedagógica dialógica, antirracista, feminista e inclusiva é também libertadora, pois se estabelece por e através do amor. Entretanto, não há estabelecimento de uma relação afetiva entre pessoas que não tiveram desenvolvida a capacidade de se conhecer e afirmar, conforme ressalta Bell Hooks, sobre a necessidade de ir além da sobrevivência.

Geralmente enfatizam nossa capacidade de "sobreviver" apesar das circunstâncias difíceis, ou como poderemos sobreviver no futuro. Quando nos amamos, sabemos que é preciso ir além da sobrevivência. É preciso criar condições para viver plenamente. (HOOKS, 2010, não paginado). 
E como poderíamos criar condições para viver plenamente sem antes entender nossa participação no mundo ou nos reconhecermos enquanto sujeitos que protagonizam a própria existência? Como alcançar um modelo de educação descolonizado se continuamos dia após dia decorando casas de bonecas sem nos preocupar com os alicerces? Nesse sentido, e a partir da visão feminista acerca da descolonização nos diz Ochy Curiel, a respeito da sociedade latino-americana.

\begin{abstract}
A descolonização no feminismo materializou-se numa espécie de busca libertadora de um discurso e de uma prática política que questiona e ao mesmo tempo propõe, que busca ao mesmo tempo que se encontra, que analisa o contexto global-local ao analisar as subjetividades produzidas por raça, classe, sexo e sexualidade, dadas neste contexto, mas que são articuladas à dinâmica estrutural. (CURIEL, 2014, p. 327, tradução livre). ${ }^{1}$
\end{abstract}

Portanto, antes é preciso que a raça, a classe e o gênero sejam pauta pedagógica norteadora dos processos que se iniciam e se estendem na sala de aula e para além dela. Não há aluno sem realidade social que o antecede, logo não há educação que se pretenda real e libertadora sem levar tais condições em análise.

Essas referências de ótica tornam-se ainda mais contundentes quando pensamos na aplicação de uma proposta pedagógica na realidade latino-americana, e especificamente na brasileira, que mesmo com similitudes, apresenta dissonâncias do que se operou/a na sociedade estadunidense descrita por Bell Hooks e Maya Angelou.

O debate entre as relações de saber e poder que se operam e a dependência das instituições na propagação de estudos feministas antirracistas e inclusivos, acadêmicos ou não é central quando se pretende que alguns estudos deixem de ser subalternizados ou particulares e pouco aplicáveis.

E exatamente nesse ponto a prática empreendida por Luana em suas turmas de Educação Fundamental se torna crucial e exemplificativa do que é necessário ser feito e do que pode de fato ser realizado, pois categoriza a realidade

\footnotetext{
${ }^{1}$ Texto original: La descolonización en el feminismo se materializó en una especie de búsqueda liberadora de un discurso y de una práctica política que cuestiona y al mismo tiempo propone, que busca al mismo tiempo que se encuentra, que analiza el contexto global-local al analizar las subjetividades producidas por raza, clase, sexo y sexualidad, dadas en este contexto, pero que están articuladas a la dinámica estructural. (CURIEL, 2014, p. 327).
} 
apresentada e alcança níveis de transformação talvez maiores do que poderíamos supor se não observássemos seus resultados.

Desse modo, assim como demonstrado na academia, os processos descolonizadores se convertem em propostas que irão questionar na prática cotidiana as relações de saber e poder, bem como as desigualdades inerentes a cada contexto social.

Através do acolhimento por e através do amor, os sentimentos que surgem em resposta à pobreza extrema, às condições inadequadas de moradia, à falta de acesso à saúde, lazer e alimentação dignas, o isolamento geográfico da cidade, o racismo, a violência, o machismo e diversas outras manifestações de preconceito e desumanidades passam a ser validados e as emoções daí provenientes não mais bloqueiam a construção do conhecimento, ao contrário, atuam como partícipes significantes do processo.

O que se opera é uma legitimação do indivíduo, que atravessa seu corpo e questões que antes só existiam no âmbito privado, muito embora fossem expressas pela maioria. Essa legitimação em consonância com um forte alicerce construído a partir da enunciação de vozes locais, não europeias, não estadunidenses promove um novo referencial que rompe com antigas suposições castradoras de quem pode produzir conhecimento e quem pode levá-lo adiante e acrescer a este. A educação operada por Luana rompe com binarismos.

Não há mais espaço para um único produtor de conhecimento e um receptor, um país que escreva a teoria, e outros que a propagam, não há um professor detentor de conhecimento e um aluno inerte, não há conhecimento puro e prática ativista, não há teorias descoladas da realidade, e é essa proposta que deve nos mover.

\footnotetext{
O pensamento e a teoria feminista latino-americana foram realmente descolonizados? Eu ouso dizer quase um ressonante não, com algumas exceções. Eu não estou propondo que nós devemos agora regionalizar nossas teorias, [o que eu estou propondo] é que um processo de descolonização deveria levar a reconhecer práticas políticas feministas que podem construir pensamento teórico na região e assumi-las não como simples testemunhos de ativismo. [...] E se as produções latino-americanas não são reconhecidas na mesma região, muito menos são conhecidas na Europa e nos Estados Unidos. (CURIEL, 2014, p. 331, tradução livre).
} 


\title{
5 HÁ UM CAMINHO POSSÍVEL [OU CONSIDERAÇÕES FINAIS]
}

A educação pautada no amor respeita as potencialidades dos indivíduos e o protagonismo da própria vida, não espera direitos dados, ao contrário fomenta em cada um o desejo de buscar e outorgar a si tais direitos, direitos estes que constituem a própria subjetividade de cada um.

Ao apresentar os Direitos Humanos a partir da prática docente e das vivências pessoais dos alunos, a educação se torna efetiva e permite que tais direitos sejam de fato vivenciados. Nesse sentido concorda a antropóloga mexicana Marcela Lagarde.

\begin{abstract}
Não se pode considerar a universalidade de uma experiência quando a condição social, sexual e de gênero é desigual. Nessa visão existencialista do amor, que o define como a realização da liberdade de cada um, a primeira coisa que nós mulheres temos que fazer é perfilar os conteúdos de nossas liberdades. Porque senão, nem sequer sabemos o que está em jogo. (LAGARDE, 2001, p. 29).
\end{abstract}

É preciso, portanto, que a educação capacite cada um, a partir do seu arcabouço pessoal para ter posse dos instrumentos garantidores da liberdade, com consciência de identidade e dos direitos decorrentes desta identidade, a fim de que as demandas sociais por uma educação conforme demonstramos se opere em toda a sociedade, conforme bem explicita Marcela, "a primeira chave para negociar no amor é ter consciência de cidadania. Essa consciência consiste em estar convencidas de que temos o direito a ter direitos e de que esses direitos devem ser respeitados pelas demais pessoas." (LAGARDE, 2001, p. 87).

Finalizo aqui com um trecho da obra da professora Luana, profundamente transformadora, não apenas pelo que está escrito em suas páginas, mas pela consistência das ações descritas ali: "é necessário compreender que a educação, assim como tudo na vida, precisa fazer sentido. Tanto para quem aprende, quanto para quem ensina", como no conto que iniciei esse artigo, não faz sentido a casa bem decorada sem luz e sem acesso. 


\section{REFERÊNCIAS}

ANGELOU, Maya. Eu sei por que o pássaro canta na gaiola. Tradução de Regiane Winarski. Bauru, SP: Astral Cultural, 2018.

CURIEL, Ochy. Hacia la construcción de un feminismo descolonizado. In: MIÑOSO, Yuderkys Espinosa; CORREAL, Diana Gómez; MUÑOZ, Karina Ochoa (ed.). Tejiendo de otro modo: Feminismo, epistemologb y apuestas descoloniales em Abya Yala. Popayán: Editorial Universidad del Cauca, 2014. p. 325-334.

FREIRE, Paulo. Pedagogia do Oprimido. 17. ed. Rio de Janeiro: Paz e Terra, 1987. HOOKS, Bell. Ensinando a transgredir: a educação como prática da liberdade. Tradução de Marcelo Brandão Cipolla. São Paulo: WMF Martins Fontes, 2013.

. Vivendo de amor. Geledés, [S.I.], 9 mar. 2010. Disponível em: https://www.geledes.org.br/vivendo-de-amor/. Acesso em: 10 fev. 2019.

KAUR, Rupi. O que o sol faz com as flores. São Paulo: Planeta do Brasil, 2018.

LAGARDE, Marcela. Claves feministas para la negociación en el amor. Managua: Puntos de Encuentro, 2001.

TOLENTINO, Luana. Outra Educação é Possível: Feminismo, Antirracismo e Inclusão em Sala de Aula. Belo Horizonte: Mazza Edições, 2018.

Recebido em 16/05/2019.

Aceito em 10/10/2019. 